\title{
La poesía chilena: Representaciones de terror y fragmentación del sujeto en los primeros años de dictadurar
}

\author{
Chilean poetry: Representations of terror and subject \\ fragmentation during the first years of dictatorship
}

\author{
Naín Nómez \\ Universidad de Santiago de Chile. Santiago, Chile \\ nnomez@lauca.usach.cl
}

\section{RESUMEN}

El objetivo de este artículo es analizar las representaciones poéticas del primer período de la dictadura chilena, con especial atención al desarrollo de las reconstrucciones políticas y estéticas. Concepciones como la razón caída, la nostalgia del paraíso perdido, la necesidad de reconstruir la historia, la búsqueda de nuevos lenguajes, van configurando un mapa de estrategias discursivas diversas tanto dentro como fuera de C hile. Todas ellas conforman una matriz singular y específica de grandes perspectivas para la producción poética posterior.

Palabras claves Poesía chilena, dictadura, representaciones simbólicas.

\section{ABST RACT}

The objective of this article is to analyze the poetic representations during the first period of the Chilean dictatorship, with special attention to the development of political and aesthetic reconstructions. Conceptions such as the fallen reason, lost paradise nostalgia, need to reconstruct history, search for new languages, configuratea map of diversediscourse strategies in Chile as well as outside the country. All of them, shape a singular and specific matrix of great perspectives for the later poetic production.

Keywords: Chilean poetry, dictatorship, simbolic representations.

Recibido: 28-02-2008. Aceptado: 15-04-2008.

* Este trabajo forma parte del proyecto Fondecyt N 01050321 titulado " ¿N eovanguardia, modernidad en disolución, postmodernidad? La poesía chilena entre 1973 y 1988", del cual soy investigador responsable. 


\title{
PREAMBULO
}

\author{
Aquí en esta pequeña parte de la ciudad \\ somos cinco mil. \\ ¿Cuántos seremos en total en las ciudades \\ y en todo el país? \\ Somos aquí diez mil manos \\ que siembran y hacen andar las fábricas. \\ Cuánta humanidad \\ con hambre, frío, angustia, pánico, \\ dolor, presión moral, temor y locura...
}

(Lara y Epple, 1978: 11-12)

\begin{abstract}
A Sí IN ICIA Víctor Jara el primer poema que se conoce escrito inmediatamente después del Golpe Militar en el Estadio Chile, con probabilidad horas antes de su asesinato. El poema, además de expresar en forma descarnada la colectivización de la represión y la tortura, se sitúa paradigmáticamente en el dispositivo del terror, como forma disciplinaria que se instauró en Chile desde el mismo 11 de septiembre de 1973. El temple colectivo de la construcción del poema, al mismo tiempo que señala lo que será el funcionamiento impersonal del terror dictatorial, inscribe en forma fehacienteel carácter anónimo y masivo que tendrán las primeras manifestaciones en contra del sistema ("cinco mil", "diez mil", "con cuánta humanidad").

D iferente era la situación de las representaciones poéticas hasta el momento del Golpe. Los tres últimos poemarios que se publicaron en 1973, bastante disímiles entreellos, son: La fundación de lasaguasdePablo G uíñez, El cansador intrabajable de Claudio Bertoni y Sabor a mí de Cecilia Vicuña, éstos dos últimos miembros de la llamada "Tribu $\mathrm{N} \mathrm{o",} \mathrm{practicantes} \mathrm{de} \mathrm{una} \mathrm{poesía} \mathrm{desarrolla-}$ da por fragmentos, fuera de toda gravedad, desprejuiciada y deudora de las premisas libertarias de los años sesenta. En el caso de Guíñez, existe una continuidad con el mundo lárico de JorgeTeillier y Efraín Barquero, incluyendo un rescate del verś́culo, del refrán, de la conseja campesina y del relevamiento del mundo natural. Tanto en ellos, como en la antología Poesía joven de Chile realizada por Jaime $Q$ uezada en ese mismo año, predomina el tono coloquial, el poema corto eirónico deudor de los poetas de los cincuenta, la visión lárica del mundo rural perdido o una ciertafijación sobreel discurso quebusca eclosionar en la autocrítica del sujeto.

Sin embargo, como he señalado en otra ocasión (N ómez, 1996: 105-126), hay poetas que dejan entrever los márgenes de un mundo que se desmorona, especialmente en el ámbito urbano. M anuel Silva Acevedo, por ejemplo, desde
\end{abstract}


Perturbaci ones de 1967 venía cavando un hueco en el mundo desencantado que vendría después. El poeta recoge la calle marginal, los retazos de la comunicación, las máscaras de sujetosfragmentados, que, como señala Grínor Rojo (1993), representan una resignación destructora que sólo conduce al autoescarnio y a una conversión desganada que se repite detrás de las máscaras. Lobos y ovejas iniciado en 1968, pero sólo publicado en 1976, es el ejemplo más claro de esa ambigüedad torcida con que la literatura precede a la historia y adopta a veces el tono de la profecía. Como quiera que lo recepcionemos, este vaticinio no deja de lado las percepciones de M anu militari (1969) ni las premoniciones de "esas águilas que perturban mi sueño... y desperté dando graznidos y cloqueando" (del poema "Las águilas"). M ario Rodríguez Fernández ha visto también en O mar Lara una segregación del mundo lárico a través de la imagen del poeta caído en tierra. En Lara, el hablante se refugia en una madriguera para continuar empollando en la oscuridad, ya que se "visual iza lo externo como un espacio abominable en su doble sentido: histórico y existencial” (1992: 152-155). También en Waldo Rojas, como lo ha señalado Javier Campos, impera el leitmotiv de la caída del ciudadano urbano con las alas rotas y la frustración del marginal. Su análisis se detiene especialmente en el poema "Pájaro en tierra" de Agua removida (1964), reeditado en Prínci pe denai pes (1966), texto del cual ha señalado Carmen Foxley, de un modo más tangencial, que expresa una visión negativa de la ciudad en donde se asiste a una disociación entre el adentro y el afuera (1991). No hay duda de que la representación que hace Rojas de la ciudad es la de una contradicción insoluble, en donde la caída de Icaro nos devuelveal frustrado vuelo del Alsino o a la caída irremediable deAltazor: "Ciel o vacío de alas es el de la Ciudad, / dominio de pájaros en tierra / con la vista baja en las plumas herrumbrosas / como esos matorrales de los parques sal picados de lodo", pero en un tono que indica que "el engaño de las alas" nos dejó "en medio del vaivén de la resaca", en otro anuncio premonitorio leído desde el futuro. También hay ecos de la destrucción en Relación personal (1968) de Gonzalo M illán donde aparece "un muñeco podrido bajo tierra en el jardín" o "un puñado ruin de aserrín sucio" y donde la ciudad ajena es el telón de fondo para la extrañeza de los amantes congelados en un cuarto: "M ientras en lo alto se iluminan/ las ruedas gigantescas y las torres, / huimos a escondernos / a un cuarto cubierto de postales... hasta quedar en la noche / de fal sos colores comerciales, / desnudos, espantados, / sin cuerpos, sin rostros, sin olores" ("Y tu piel me es doblemente extraña"). El propio ( ampos había criticado la supuesta disyunción que parecía existir en la poesía chilena anterior al Golpe: "La atmósfera desgarrada y escindida, la que reconocía como uno de los rasgos más recurrentes en la joven poesía, adolecía de una significativa comprensión que la enmarcara dialécticamentecon 
su tradición, aquella específica formalización señalada y el particular contexto nacional y continental. Como nada de esto se problematizaba, no quedaba más que reducirla a términos más o menos vagos como 'poesía alienada', 'hermética', 'no comprometida', en fin, poesía personal y enajenada, incapaz de dar cuenta delas luchas sociales, históricas y del entonces contexto chileno en lo queiba de 1961 a 1973" (1987: 18). C oncuerdan con esta visión los autores de la antología Las plumas del colibrí referida a la poesía de Concepción durante el período dictatorial y lo ratifican con la afirmación de varios críticos que se refieren a la época anterior: Jaime C oncha, Juan Armando Epple, Jaime Giordano y Federico Schopf. Para los autores de la antología, las resquebrajaduras tienen más que ver con "el desajuste visible entre la naturaleza triunfalista del discurso ideológico de la izquierda en los años setenta y el agonismo del decir poético instalado en la cada vez más problemática realidad". A juicio de los editores, "Ios sucesos de 1973 historizaron no sólo la escritura poética, sino también sus múltiples posibilidades de lectura... " (Alonso et al., 1989:11-52).

\section{LA POESIA EN LOS PRIMEROS AÑ OS DE DICTADURA}

Es por lo tanto esta línea de continuidad la que nos interesa desarrollar aquí, para dejar claro que el movimiento de la producción poética chilena no se pierde ni se corta, sólo se transforma en el proceso de los primeros años de dictadura, cuando el reordenamiento de la institucionalización autoritaria de la dictadura obliga a los poetas del interior del país a la autocensura, la escritura panfletaria, la protesta comprometida y la búsqueda de nuevas fórmulas escriturales para dar cuenta de una realidad reprimida, escindida, fragmentada.

En éste, el período más oscuro de la fase terrorista del sistema dictatorial, cuando impera el orden del terror cuyo efecto son los detenidos desaparecidos, se acelera -al comienzo un poco caóticamente y luego de manera más ordenada- la institucionalización autoritaria de la dictadura. Los primeros días y meses fueron sintomáticos de este ordenamiento ejemplarizador en que la razón de Estado está por sobre los individuos con el fin de derrotar el M al: ejecución de los colaboradores de Allende, campos de concentración en el sur y norte del país, torturas especialmente sobre los miembros de las Fuerzas A rmadas considerados traidores, exilio, casas de tortura. A las ejecuciones directas de los primeros tiempos siguieron los enfrentamientos verdaderos y falsos posteriores y finalmente las desapariciones que se extienden más allá del inicio del transformismo dictatorial iniciado alrededor de 1977.

Además del poema de Víctor Jara, inmediato y testimonial, tenemos otros textos que nos ayudan no sólo a reconstruir la mirada del sujeto vejado en su 
mínima condición humana, sino también que nos muestran las formas resignificadas que adopta el testimonio bajo la represión: "El testimonio, tradicionalmente la expresión literaria que corresponde a la necesidad de verbalizar experiencias sociales y personales extremas, decisivas y traumáticas en la historia de un hombre o de una nación, es una modalidad reconocible en la poesía que se escribe en Chile en los años inmediatamente posteriores a 1975" (Alonso et al., 1989: 30). Para los autores, "el testimonio lírico, memoria inmediata, fijación lingüística de instantes de dolor, del horror, se (auto) percibe como discurso real frente a la irrealidad mistificadora creada por los periódicos, la TV, los comunicados oficiales. Los testimonios muestran el carácter humano de los 'M onstruos', del 'enemigo', del otro recluido en los lugares de castigo y purificación... casi todos los textos narran una historia, una situación que siendo individual adquiere una dimensión social, borrando la distinción entre lo privado y lo público. Lo que le ocurre al sujeto no es una mera cuestión personal. Su carácter de víctima correspondea la situación detodo un conglomerado social y las 'historias' son comunes a muchos hombres" (I bíd, 31 y 33). La aparición de un sinnúmero de panfletos, textos mimeografiados, volantes, actos culturales relámpagos o incluso reuniones de grupos de amigos hechas en forma privada, reemplazan lasformas públicas de diseminar las producciones literarias que adoptan ahora una clara intencionalidad política. Yaa partir de los años 1975 y 1976 empiezan a editarse una serie de revistas que de manera más sistemática intentan entregar a un número reducido de lectores los primeros fundamentos de una literatura crítica que utiliza los espacios en blanco, la supresión, la sustitución, la inversión y otros códigos de mediación retórica, que buscan eludir la censura, así como también nuevas formas de expresión. En esta línea aparecen las revistas Envés dirigida por M ario M ilanca, Carlos Cociña y N icolás M iquea y Vértice en Concepción; el grupo y la revista Aumén creada por C arlos Trujillo y Renato Cárdenas y Archipi élago de M ario Contreras Vega en Chiloé; en Punta Arenas la revista M omentos iniciada por Luis Alberto M ansilla y Aristóteles España; Poesía para el camino de Ricardo W illson, El 100topiés de Luis A ravena y Esteban N avarro, La Castaña de Jorge M onteal egre y Eduardo Llanos, H uelén de H ernán O rtega y Jorge C alvo, La Gota Pura de Leonora Vicuña y Ramón D íaz Eterovic y La Bicicleta de Eduardo Yentzen en Santiago. Esta enumeración debe ser sin duda todavía muy incompleta. Uno de los primeros escritos "testimoniales" es el del joven de 17 años Aristóteles España, recluido en el campo de concentración de $D$ awson, quien publica en forma artesanal una serie de poemas escritos entre septiembre de 1973 y julio de 1974 con el nombre de Equilibriose incomunicaciones, para luego editar una versión definitiva con el nombre $D$ awson en 1985, con un prólogo de Jorge Narváez y un escrito en la contratapa de Alfonso Calderón. Con el mismo tono admonitorio de Jara, el discurso de Es- 
paña tiene, sin embargo, una elaboración diferente. El sujeto poético no sólo pregunta, se queja, se angustia, se enrabia con la situación imperante, sino que también cuestiona, proyecta, denuncia y, por sobre todo, describe como un cronista angustiado ("hago preguntas, anoto, observo todo lo que ocurre"), pero obligado a describir conscientemente de lo que ve:

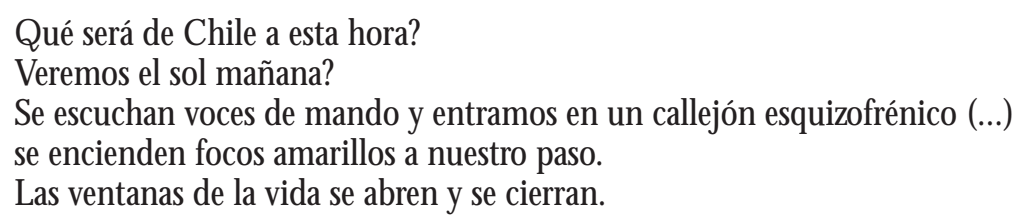

(“Llegada”)

Esta aguda visión de la realidad se incrementa al percibir los medios de tortura y prisión como una extensión de los propios torturadores. Así es como el cerco de púas de alambre se transforma en una metonimia de la gran prisión que es el país:

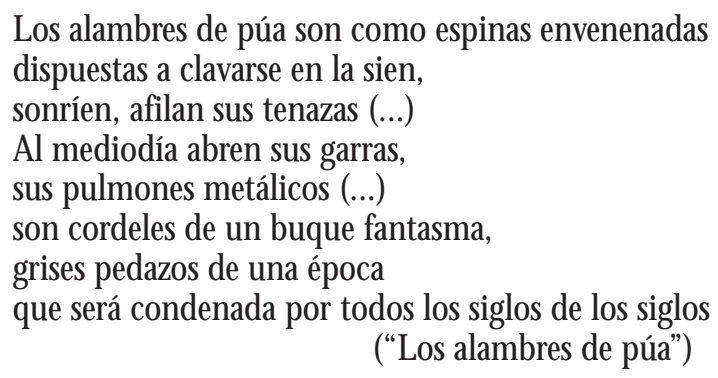

La antropomorfización represora del alambre busca el efecto de entregar al lector la atmósfera terrorífica del lugar, así como la acción degradadora y mecánica de su acción, pero que no puede ahogar la proyección histórica que se refugia en la condena futura.

D el mismo tenor es Carta de prisionero de Floridor Pérez, publicado definitivamente en 1984, pero que incluye poemas de fines de 1973 escritos en la I sla Q uiriquina donde el poeta estuvo recluido. El humor aparece como forma de escape pero también como técnica de corrosión crítica frente a la represión y la tortura: "Todavía me pregunto por qué tú / - por qué tú y no yo- / por qué tú que alzabas gordos sacos / y cargabas camiones / eras fuerte, degollabas carneros/ ipor qué no te aguantaste ese viaje / en un camión cargados como sacos / y te tiraron muerto junto a mí / con tu poncho de pobre / como un carnero blanco degollado/ por quétú, por la cresta, y no yo / queni me puedo el diccionario/ de la Real Academia en una mano?" ("In M emorian”). 
Es sabido que la mayor parte de la poesía del momento se hace en las cárceles, en los campos de concentración o en el repliegue de los hogares sitiados, para pasar de mano en mano, ser publicada en al guna revista artesanal de carácter clandestino o viajando subrepticiamente fuera del país para ser editada en al guna revista del exilio. En muchos casos se trata de poetas improvisados, que buscan expresar su explosión de dolor, frustración y rabia a través deun discurso espontáneamente literario. Por otro lado, poemas anónimos son posteriormente reconocidos por poetas que salen al exilio. "A una lavandera de Santiago" fue publicado primero anónimamentey luego reconocido por el poeta $\mathrm{O}$ scar $\mathrm{H}$ ahn. Lo mismo ocurrió con el texto "Q ué digiera bien, señora", reeditado por Ana M aría Vergara. Este último logra, a través de la intensificación de la pregunta y el símbolo/metonimia dela cacerola llena en oposición a la "marcha de las cacerolas vacías" realizada por las mujeres de la burguesía en 1972, mostrar de una manera fehaciente los momentos de terror que se viven en el país:

$$
\begin{aligned}
& \text { ¿Está llena } \\
& \text { su cacerola } \\
& \text { ahora, señora? } \\
& \text { ¿D e qué? } \\
& \text { ¿D e carne? } \\
& \text { ¿D e hígado? } \\
& \text { ¿D e lengua? } \\
& \text { ¿D e qué } \\
& \text { está llena } \\
& \text { cree usted, } \\
& \text { señora, } \\
& \text { su cacerola? }
\end{aligned}
$$

("Q ue digiera bien, señora")

Lasimple reiteración dela pregunta en diversos tonosy el contexto social en que se formula, le dan una resonancia irónica, política y trágica a la vez a la interpelación del sujeto.

En forma anónima también apareceen una antología de 1978 (Lara y Epple: 21), un poema de $\mathrm{O}$ scar $\mathrm{H}$ ahn escrito poco después del $\mathrm{Golpe}$, en donde de manera coloquial que no deja de lado la ironía da cuenta de la situación:

Se terminó este año cabrón. Se fue a la cresta. Se fue completamente a pique: capotó. Con sus terrores y llantos y entierros a cuestas y los cuatro jinetes del apocalipsis.

(“Año viejo 1973") 
Los poemas anónimos escritos en el país dentro de esta corriente irónica y denunciatoria, muchas veces transcritos fuera de él, se multiplican. Un ejemplo es el poema "Electra” aparecido en la antología de Sergio M acías:

\author{
M e desnudé nervioso \\ con la misma zozobra de mis 18 años. \\ Y me tendí en tu cama extraña. \\ C osa curiosa: ataron tu lecho a mis espaldas, \\ para que no me moviera. \\ Inesperada, recorriste mi cuerpo, \\ induciéndome espasmos crueles. \\ No, no haré más el amor contigo. \\ M ujer vulgar y corriente.
}

M ientras, la ofensiva cultural oficial se refugia en la Secretaría de la Juventud y en los mecanismos tradicionales de las casas culturales y las asociaciones controladas, utiliza también el despliegue publicitario del Festival de Viña del M ar - la reinvención de las Fiestas Primaveral es con el beneplácito de algunos escritores (Enrique Lafourcade, Braulio Arenas, José Luis Rosasco, Carlos Iturra...), muy pocos, que se dejan adular para insertarse en los espacios vacíos de la cultura pública.

\title{
LA POESIA DEL EXILIO
}

En el exterior, las primeras manifestaciones son de dolor, angustia, rabia, deseos de recobrar el paraíso perdido, poemas de batalla con mayor o menor carga simbólica dependiendo de la experiencia, la madurez, la profesionalización del poeta. Alfonso Alcal de escribe sobre "el último sonido/ que todavía escucho de Chile / al fondo de mis 40 mil muertos" ("Golpe tercero") y señala que "el mar subió en un $450 \%$, / el dolor en un 78,3\%, / laira en un $1.234 \%$ / ... y la muerte un 5.678\%" ("Golpe duodécimo"). Ligeia Balladares dirá que "se me olvidó el amor/ pero también/ seme olvidó el olvido" ("Exilio"). Efraín Barquero emulará los Bandos marciales (1974), con un tono irónico pero también dolorido: "No somos gorilas/ como se ha dado en llamar a los hombres razonables. / N os distinguimos del hermano gobierno del Brasil/ en una cosa muy importante: el clima" ("Bando 203"). U na visión más desgarrada, cercana a la tragedia griega adopta su libro El poema negro de Chile también de 1974, con su visión apocalíptica que muestra el fin de la solidaridad familiar y colectiva: "En esta hora somos la familia diezmada / y tú, madre, eres la sombra más espesa / donde un niño viene a sentarse en un rincón / con un gallo moribundo entre los bra- 
zos" ("La familia diezmada”). Por su parte, Roberto Bolaño y Bruno M ontané describen un mundo cotidiano en que "pasa la patrulla, / los almacenes cierran temprano. / En la noche las farmacias / huelen a cuartel./ 0 tro día/ y los niños van a la escuela/ para volver llorando / impresionantes cadáveres / pegados a sus ojos" ("C arta"). O mar Lara remeda la crónica cuando escribe: "D el grupo de encantados que escuchábamos tus historias... ya no queda ninguno, / estamos desperdigados. Yo en el Perú, / de los otros no tengo noticias" ("H ablo de Luis 0 yarzún, del río Valdivia, etc."). Por su parte, G onzalo M illán hace también de cronista para contar la historia del otro: "M e contó: Algunos/ compañeros crecen / por entre las rejas / y a la calle salen, / de la alcantarilla/ como helechos" ("Cárcel"), crónica que a su modo retoma Armando U ribe al utilizar la voz de diversos testigos del crimen: "N o puedo hablar y no hablo. / N i puedo ver. No veo. / M e han declarado reo. / Dicen que soy el diablo. / El asno dice: entablo / juicio, y el buey: lo creo / O mnipotente D eo / Chile está hecho un establo" ("Los quince testigos del crimen"). Y un último ejemplo de esta versión del cronista-testigo (pero ahora desde la muerte), lo encontramos en Gonzalo Rojas: "Entonces nos colgaron de los pies, nos sacaron / la sangre por los ojos, / con un cuchillo / nos fueron marcando en el lomo, yo soy el número 25.033, /nos pidieron/ dulcemente, / casi al oído, / que gritáramos / viva no se quién. Lo demás / son estas piedras que nos tapan, el viento" ("D esde abajo").

En 1975 pareciera que el apagón cultural empieza a disolverse para dar paso al transformismo del régimen dictatorial quetiene su momento más decisivo en 1976, después del asesinato de 0 rlando Letelier, la desaparición de la dirección clandestina del Partido Comunista y las primeras señales de la división de la cúpula militar. Algunos atisbos de una apertura mínima en el campo cultural, más bien movimientos esporádicos de despliegues que pronto se cierran y obligan al repliegue sistemático de los poetas y que se exteriorizan en ediciones como la de Julio Barrenechea, que colecciona sus poemas en Voz reunida (1975) o Por fuerza mayor (1975) de Enrique Lihn, que en verdad se publicó en Barcelona y que fue escrito a fines del año 1974. Algunos de los poemas de estelibro serán reeditados más tarde en Estación de los desamparados (1982). Un hito de ese momento lo representa la publicación de la revista M anuscritos cuyo primer y único número se publicó ese mismo año bajo la dirección de C ristián H uneeus y Ronald Kay. Con trabajos deK ay y H uneeus, además de R aúl Zurita, N icanor Parra y Jorge G uzmán, la revista es no sólo un suceso literario, sino también un cambio en lo estético, ya queincluye collages, fotografías, quebrantahuesos (textos realizados con avisos de periódicos) y diversas rupturas formales con la página, empezando por el formato mismo de la revista de gran extensión cuadriculada. La revista M anuscritos representó no sólo una clausura del apagón cultural, sino una forma encubierta de rehuir la censura: ¿qué sentido tenían esas vacas perdi- 
das en el espacio de un campo ampliado al infinito en el texto "Areas verdes" de Zurita? 0 ese collage de textos parrianos en que la crítica y la apertura asoman ambiguamente detrás de cada frase: "campo de tensiones", "conjunto de lo excluido", "temporalidad vista en expansión", "noticia libre de controles", "revisión de sus propios desechos, de su propia represión", "marginalidad específica" o los textos irónicos de "M isión cumplida". La revista, indudablemente hizo un paréntesis en la oscuridad cultural del momento y trajo un aire desconcertantemente fresco a la situación intelectual del momento.

A partir de fines de 1975 y hasta 1977, los signos de apertura se hacen más evidentes. Por un lado, como señala Moulián, se instauró el monopolio del saber desde la instalación de las políticas de la dictadura como verdades científicas deducibles, que tienen como centro el terror por un lado y el derecho por otro. Se instaló la Escuela de Chicago como la ciencia económica oficial y el tratamiento de shock hizo que los años 1975 y 1976 fueran años de penuria en lo económico. Con el cambio que se inicia en 1977 y el boom que dura desde ese año hasta 1982, además de la legitimación de la represión con los principios jurídicos de las Actas Constitucionales de 1976, se subordina el derecho al terror y se define la "nueva democracia" como "autoritaria, tecnificada, integradora y de participación social". Abatidos los grupos políticos y sociales más radicales de la sociedad chilena, la Junta de G obierno pudo permitir abrir ciertas brechas en lo cultural en paralelo a las libertades económicas, que nunca se revirtieron en lo político en esos años.

Se editan nuevos libros de poemas que tímidamente muestran entre sus versos al gunos vestigios de crítica, bajo los escombros de un sujeto generalmente fragmentado, vacío, exiguo, marginado, dolorido. Es el caso de un texto mimeografiado de Jorge Torres U lloa titulado Recurso de amparo (1975), que circuló restringidamente y que representa uno de los primeros escritos que introduce lo político de una manera aún subrepticia. Durante el año 1976, son varios los poemarios que, de la misma manera solapada, entran al campo cultural en ediciones de pocos ejemplares y con distintas posiciones estéticas: L os granos y las hojas de Jorge J obet, que vuelve los ojos hacia la tradición rural del sur del país buscando símbolos de proyección; Astrolabio y otros poemas de Jaime Q uezada, con su dejo de nostal gia hacia un mundo perdido y breves referencias irónicas a la situación que se vive; El jardín de las palabras de Jonás, quien inquebrantablemente continúa su línea de vinculación con un mundo natural esencial, en una búsqueda que se da también fuera de la realidad imperante. D el mismo año son V értigo de D aisy Bennett y Al umbral de la luz de Inés M oreno, quienes en su discurso minimalista representan la situación del ciudadano corrienteen un mundo ajeno. Por ejemplo M oreno: “Sola / en la estación M apocho / con un abrigo que te queda largo / y una niebla / que / se / arrastra / y / te enfría 
el corazón" ("Sensaciones") o "... Tirar una piedra al vacío / y sentir / su rebote / sordo / en tus propios huesos" ("D onde está la luz?"). El verso entrecortado de estos poemas aúna el canto triste y sollozante de la sujeto con su propia fragmentación representada en la forma del verso. $\mathrm{H}$ ay quemencionar la importancia del ya citado Lobosy ovejas de M anuel Silva, publicado en 1977, pero escrito mucho antes y ampliamente leído entre los poetas exiliados que le incorporan nuevas claves y significados en función de las transformaciones, los engaños y las apariencias de la sociedad chilena:

\author{
$H$ ay un lobo en mi entraña \\ Q ue pugna por nacer \\ M i corazón de oveja, lerda criatura, \\ Se desangra por él.
}

H acia 1977 el abanico de expresiones poéticas se amplía de manera expectante. Por un lado, los poetas jóvenes desarrollan una lírica comprometida políticamente, pero también con resonancias simbólicas vastas. Es el caso de José M aría M emet, con su primer libro Poemas crucificados, del segundo libro de Jorge TorresU Iloa, Palabras en desuso, y de publicaciones en revistas y antologías deErick Polhammer, Antonio G il, Bárbara D élano, D iego M aquieira y Ricardo Wilson, entre otros. En varios de ellos se destaca la ironía, el juego de palabras, la utilización de elementos de la publicidad, el pastiche, el collage, el uso de la página en blanco, las formas visuales y otras técnicas de carácter experimental. Es el caso por ejemplo de Diego M aquieira, quien anuncia en U psilon (1975) el sujeto desdoblado y oralizado de La Tirana (1983). Antonio Gil publica algunos poemas en la antología deW illson (1977), en queel sujeto sedespersonal iza y los objetos cobran una dimensión demencial. Por su parte, Erick Polhammer escribe a medio camino entre un tímido vanguardismo y una crítica feroz a la dictadura, representada de manera valiente en sus poemas "Los helicópteros" y "Algo que no tiene nombre le ha ocurrido al gallo". En el primero, con una circularidad expresiva que alude a la repetición mecánica de la tortura, aparecen los helicópteros con su presencia martirizante: "... hasta que llegaron los helicópteros y los helicópteros / se establecieron desde allí hasta siempre / girando y zumbando como tábano / de acero los helicópteros / girando sobre nuestros cerebros, zumbando sobre nuestros cerebros". La poesía deM emet, TorresU Illoa, Bárbara D élano y Ricardo W illson se centra más en lo político y las representaciones de una individualidad comprimida y alienada.

En el mismo año, Alfonso Calderón publica Isla de los bienaventurados, un despliegue fantasioso de homenajes a personajes vivos y muertos escrito en verso tradicional y donde parece que la realidad del momento estuviera ausente. A 
ello habría que agregar la publicación de París, situación irregular de Enrique Lihn y Sermones y prédicas del Cristo deElqui de N icanor Parra, los cual es elaboran claves para hablar en forma velada de la censura y la violencia a través de la parodia, la sátira y la ironía.

\section{IRRUPCION DE LA RUPTURA, RESIGNIFICACION DE LA CONTINUIDAD}

El período se cierra (o más bien se abre) con algunos poetas de ruptura que publican sus primeros libros en 1977: me refiero fundamentalmente a Juan Luis M artínez con La nueva novela y a Raúl Zurita con Purgatorio en 1979. Ambos libros se empezaron a escribir varios años antes y fragmentos de los mismos aparecieron en revistas o fueron leídos ante públicos esporádicos desde comienzos de los años setenta. M artínez se plantea destruir los supuestos textuales y extratextuales de la escritura poética y horada su propio discurso como totalidad sin fisuras. Su intento es lograr la despersonalización total del texto. Por su parte, Zurita busca superar la noción de texto para incorporar el espacio del cuerpo y la realidad como soportes de la escritura, explorando también las posibilidades traumáticas del dolor para metaforizar las agresiones sufridas por el cuerpo social. Para ello utiliza los el ementos de la escatología cristiana, especialmente los símbolos del mesianismo y la revelación. La obra de Zurita tiene una evidente filiación con Juan Luis M artínez y con otros poetas coetáneos que empiezan a publicar libros en forma posterior, como es el caso de Juan Cameron, D iego M aquieira, Gonzalo M uñoz, Rodrigo Lira y Eugenia Brito. En todos ellos se produce la búsqueda de nuevos significantes y espacios de escritura, la elaboración de el ementos gráficos que dialogan con el texto escrito, la despersonalización del sujeto o la entrada en escena de sujetos fragmentados, escindidos o múltiples, la autorreflexibilidad y la inter-acción arte-vida, que expresan una vuelta de tuerca hacia las vanguardias en otro momento de la espiral del movimiento literario.

Terminamos parcialmente este recuento descriptivo con la apertura que representan dos antologías de valor dispar, pero que interpretan un fenómeno más amplio desde el punto de vista cultural entre 1977 y 1978. N os referimosa Poetas chilenos dehoy (Tomo I) de 1977, una selección de D aisy Bennett y Ariel Fernández, editado por Tamarugal, con poetas que pertenecen al grupo-taller literario del mismo nombre y donde sin grandes pretensiones se aprecia el interés por diseminar producciones de poetas jóvenes. M ás selectiva es la antología de 1978 titulada Poesía para el camino realizada por la U nión de Escritores Jóve-

nes dirigida por Ricardo W illson. Encabezada por un prólogo de Roque Este- 
ban Scarpa, una explicación del presidente de la U nión de Escritores Jóvenes y un manifiesto de Fidel Sepúlveda Llanos; la antología contó con el apoyo de la Editorial de la Universidad Católica y desarrolló una crítica más frontal que otras publicaciones anteriores. Su gestor, Ricardo Willson, dirá en el prólogo que "ha quedado atrás el café con sus conversaciones de cuatro sillas... iPerdón...! la joven poesía sale a la calle". Para luego agregar que "esta antología es, o pretende ser, la continuidad del oficio poético que heredamos de las generaciones anteriores a la nuestra". Al situarse como una continuación de la tradición, la antología inicia una rearticulación histórica, un diálogo que intenta romper la fragmentación de la cultura que ha propugnado la dictadura durante esos años. Entre los poetas de la selección, reconocemos a varios que serán actores importantes de la cultura de esos años, como es el caso de Armando Rubio, Paula Edwards, Erick Polhammer, Antonio G il, Bárbara D élano, Ricardo W illson y sus prologuistas. Fidel Sepúlveda Llanos coloca la piedra angular de los planteamientos de la antología al titular las cuatro partes de su manifiesto: "Poesía: artículo de primera necesidad", "Poesía: repliegue y despliegue del sentimiento", "Poesía: conciencia de Chile" y "Poesía: conciencia deAmérica”. Por primera vez desde los inicios de la dictadura, se muestra la puesta en escena de la poesía como un actor fundamental en la actitud contestataria que los grupos sociales tendrán a partir de ese año en el país. Esuna resignificación fundamental del intercambio entre lo cultural y lo político, transformación que relevará el papel de la cultura durante todo el período dictatorial tanto por su rol crítico frente a la represión, como por los desarrollos estéticos que le dan un nuevo impulso a la formalización de sus lenguajes.

Pensamos que aquí ya se avisoran al gunas de las problemáticas que el $\mathrm{G}$ olpe militar establece con el proceso de la modernidad y la manera como los poetas perciben este cambio y las subsecuentes transformaciones: ¿Cómo fenómeno premoderno? ¿Cómo una modernidad diferente frente a la cual la poesía se vuelca al pasado para dar una respuesta antimoderna? ¿C ómo un deseo de resignificar la modernidad anterior al Gol pe? ¿Cómo una manera de reconstruir una historia que se había convertido en un proyecto único y unidimensional? Estas y muchas otras posibilidades empiezan a aparecer en la poesía del período. Si el Golpe militar pudo ser leído como un estadio más de la modernidad, un cambio que tuvo el propósito de acabar con un pasado que se agotaba, la lírica anterior representaría diversas alternativas de un discurso retrógrado que buscaría criticar esa modernización. Al elegir ésta como la alternativa menos plausible, especialmente si se consideran los registros de una violencia desbordada e irracional, habría que plantearse la idea del quiebre democrático como un fenómeno premoderno, un retroceso hacia la caída del espíritu hegeliano que borra los principios humanistas que han gobernado 0 ccidente durante los últimos 
tres 0 cuatro siglos. Esta teleología de la modernidad ilustrada donde la historia poseía una meta y el ser humano debía convertirse en el artífice de esa historia, es la que predomina con diversos matices en Ia lírica del período. Es por ello que se multiplican los discursos reflexivos que buscan enfrentar la irracionalidad de los sujetos dominantes y represores, con una visión que racionaliza la historia y que todavía débilmente se proyecta hacia el futuro. El sujeto poético es un suje to moderno que se siente violentado y mutilado en sus derechos adquiridos a lo largo de una historia, cuya teleología es parte de un acervo común y está inscrita en los genes de la memoria colectiva. M omento todavía de recepción y reflexión, de reciclaje de la experiencia, de reacción más que de acción, de acusar el Golpe más que de devolverlo, de reunir fuerzas para desarrollar una actitud contestataria. Pero momento también de la maduración de diversas matrices discursivas que darán origen a una diversidad de la poesía chilena que tal vez nunca antes tuvo, con la conocida excepción de la época de las vanguardias. D e esos dolores venimos y la compleja gama de los nuevos lenguajes literarios, especialmente poéticos que hoy día surten a las generaciones recientes, se templó y conformó en aquellas difíciles circunstancias. En los años ochenta, el abanico se iba a ampliar en formatransversal desdeel punto devista geográfico nacional einternacional, de género, de tendencias discursivas, de generaciones, etc. Pero ese desarrollo tiene que ver con otros trabajos.

\section{REFEREN CIAS}

Alonso, M aría N ieves, Juan Carlos M estre, M ario Rodríguez y G ilberto Triviños. 1989. Las plumas del colibrí. Q uinceaños de poesía en Concepción (1973-1988). Santiago, Chile: Improde/Cesoc.

Barrenechea, Julio. 1975. Voz reunida. Santiago, Chile: Editora Nacional Gabriela M istral.

Barquero, Efraín. 1974. El poema negro de Chile M éxico: Siglo Veintiuno Editores.

Bennett, D aisy y Ariel Fernández. 1977. Poetas chilenos de hoy. Tomo I. Santiago, Chile: Sociedad de Escritores de Chile.

Campos, Javier. 1987. La joven poeśa chilena en el período 1961-1973 (G. M illán, W. Rojas, 0 . Hahn). Concepción, Chile: Ediciones Lar.

Calderón, Alfonso. 1977. I Sa delos bienaventurados. Santiago, Chile: N ascimento.

España, Aristóteles. 1985. D awson. Santiago, C hile: Editorial Bruguera.

Foxley, C armen y Ana M aría Cuneo. 1991. Seis poetas de los sesenta. Santiago: Editorial Universitaria.

Gómez Rogers, Jaime (Jonás). 1976. El jardín delaspalabras. Santiago, Chile: Ediciones Paulinas.

Guíñez, Pablo. 1973. La fundación de lasaguas. Santiago: Ediciones del Grupo Fuego de la Poesía. 
H ahn, 0 scar. 1995. Versos robados. M adrid: Visor.

Jobet, Jorge. 1976. L os granos y las hojas. Santiago, C hile: N ascimento.

Lara, O mar y Juan Armando Epple. 1978. Chile: Poesía de la resistencia y el exilio. Barcelona: Editorial Ambito Literario.

Lihn, Enrique. 1975. Por fuerza mayor. Barcelona: 0 cnos.

- - - - . 1977. Paríssituación irregular. Santiago, Chile: Ediciones Aconcagua.

- - - - . 1982. Estación de los desamparados. M éxico D .F.: Premia Editora.

M acías, Sergio. 1990. "Una breve aproximación a 16 años de poesía chilena 19731989", Cuadernos Americanos 482-483, pp. 177-196.

M aquieira, Diego. 1975. U psilon. Santiago, Chile: Printer Ltda. (autoedición).

- - - - - . 1983. La Tirana. Santiago, Chile: Tempus Tacendi.

M artínez, Juan Luis. 1985. La nueva novela. Santiago, Chile: Ediciones Archivo.

M illán, G onzalo [1968]. 2006. Relación personal. Santiago, Chile: Ediciones U D P.

M oulián, Tomás. 1997. Chileactual: Anatomía deun mito. Santiago, C hile: Lom Ediciones.

N ómez, N aín. 1996. "M arginalidad y fragmentación urbana en la poesía de los sesenta: un cuestionamiento al sujeto poético de la modernidad". Atenea 474, Universidad de Concepción, Segundo Semestre, pp. 105-126.

Q uezada, Jaime (ed). 1973. Poesía joven de Chile. M éxico: Siglo XXI.

Q uezada, Jaime. 1976. Astrolabio. Santiago, Chile: N ascimento.

Parra, N icanor. 1977. Sermones y prédicas del Cristo de Elqui. Val paraíso: Ganymedes.

Pérez, Floridor. 1984. Cartas de prisionero. M éxico, D .F.: C asa de Chile.

Rojas, Waldo. 1964. Agua removida. Santiago, Chile: Ediciones Boletín del Instituto Nacional.

- - - - . 1966. Príncipe de naipe Santiago, C hile: Ediciones M imbre.

Rojo, Grínor. 1993. Poesía chilena del fin dela modernidad. Concepción: Universidad de Concepción.

Silva Acevedo, M anuel. 1967. Perturbaciones. Santiago, C hile: Ediciones Renovación.

- - - - - . 1976. Lobos y ovejas. La Florida, Chile: Ediciones Paulinas.

- - - - - - . 1988. M anu militari. Santiago, Chile: Ediciones M elquíades.

Torres U lloa, Jorge. 1978. Palabras en desuso. Chile: edición particular.

Vicuña, Cecilia [1973] 2007. Sabor a mí. Santiago, Chile: Ediciones Universidad Diego Portales.

Willson, Ricardo (ed.). 1977. Poeśa para el camino. Antología. Santiago, Chile: Ediciones N ueva U niversidad.

Zurita, Raúl. 1979. Purgatorio. Santiago, C hile: Editorial Universitaria. 